\title{
Radiocarbon dating of human burials from Raqefet Cave and contemporaneous Natufian traditions at Mount Carmel
}

\author{
Omry Barzilai ${ }^{1,2, *}$, Noemi Rebollo ${ }^{1,3}$, Dani Nadel ${ }^{4}$, \\ Fanny Bocquentin ${ }^{5}$, Reuven Yeshurun ${ }^{4}$, György Lengyel ${ }^{6}$, \\ Gal Bermatov-Paz ${ }^{4} \&$ Elisabetta Boaretto ${ }^{1}$
}

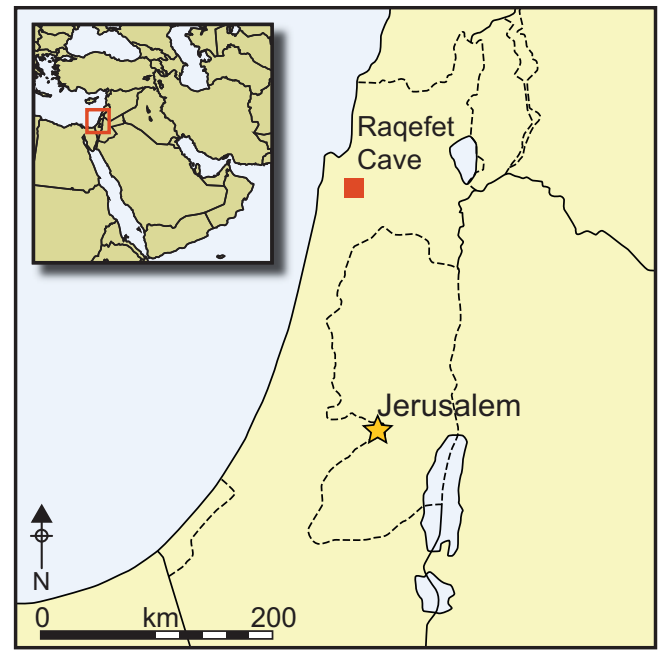

The Natufian culture (c. 15-11.5 ka cal BP) marks a pivotal step in the transition from hunting and gathering to sedentism and farming in the Near East. Although conventionally divided into Early and Late phases, this internal chronology lacks support from reliable absolute dates. This is now addressed by new AMS dating from two neighbouring Natufian sites at Mount Carmel in Israel: Raqefet Cave, conventionally assigned to the Late phase of the Natufian; and elWad Terrace, spanning the entire Natufian sequence. Results indicate that these two sites were in fact contemporaneous at some point, but with distinct lunate assemblages. Distinguishing between Natufian phases is, therefore, more complex than previously thought; the social implications of diverse but co-existing cultural manifestations must be considered in any future reconstruction of the Natufian.

Keywords: Levant, Israel, Raqefet Cave, el-Wad, Natufian

1 Max Planck-Weizmann Center for Integrative Archaeology and Anthropology, D-REAMS Radiocarbon Laboratory, Weizmann Institute of Science, Rehovot 76100, Israel

2 Archaeological Research Department, Israel Antiquities Authority, POB 586, Jerusalem, Israel

3 Institute of Geology, Universidad Nacional Autónoma de México, Ciudad Universitaria, 04510 México D.F., Mexico

4 Zinman Institute of Archaeology, University of Haifa, 199 Aba-Hushi Avenue, Haifa 3498838, Israel

5 French National Center for Scientific Research, UMR 7041, 21 allée de l'Université, 92023 Nanterre Cedex, France

6 Department of Prehistory and Archaeology, University of Miskolc, Egyetemváros, H-3515 Miskolc, Hungary

*Authors for correspondence (Email: omry@israntique.org.il; elisabetta.boaretto@weizmann.ac.il) 


\section{Introduction}

The Natufian was a semi-sedentary hunter-gatherer culture that occupied the Levant during the Terminal Pleistocene (e.g. Belfer-Cohen 1991; Valla 1995). Natufian sites in the Mediterranean woodland area of the southern Levant include curvilinear structures with stone foundations, intensively used cemeteries with diverse burial customs, ground stone tools and bedrock features, decorated art objects and evidence for dog domestication (Davis \& Valla 1978; Belfer-Cohen 1988; Valla 1988; Weinstein-Evron 1998; Bocquentin 2003; Dubreuil 2004; Rosenberg \& Nadel 2014). As such, the Natufian culture was innovative in many ways. Natufian subsistence relied on systematic plant gathering and processing, evidenced by flint sickle blades and ground stone tools, and by the intensified hunting of gazelles and small game (Unger-Hamilton 1991; Dubreuil 2004; Munro 2004; Edwards 2006; Bar-Oz et al. 2013; Yeshurun et al. 2014). These practices are considered to have played a major role in initiating the 'agricultural revolution' in the Near East, thereby lending special importance to the accurate determination of their chronologies (e.g. Valla 1995; Belfer-Cohen \& Bar-Yosef 2000).

The geographic expansion of the Natufian is broadly divided into two provinces: the Mediterranean woodland area and the more arid belt (Belfer-Cohen \& Goring-Morris 2013; Goring-Morris \& Belfer-Cohen 2013; Richter et al. 2014). The settlement pattern in the Mediterranean area, where Raqefet Cave is situated, includes semi-permanent settlements and other sites that were probably designated for burials (Figure 1). The latter are considered indicators of "boundaries between various regional groups" (Goring-Morris et al. 2009: 205). Some of the Natufian graves display complex funerary practices reflecting an elaborate social system (Garrod \& Bate 1937: 14-19; Belfer-Cohen 1988; Byrd \& Monahan 1995; Bocquentin 2003; Grosman et al. 2008; Nadel et al. 2013).

\section{Natufian chronology}

The rich archaeological record is used for determining the relative Natufian chronology and is conventionally divided into Early and Late phases, although some scholars (e.g. Valla 1995) divide it into three phases: Early, Late and Final. This paper follows the two-phase division that combines the Late and Final into a single phase. The most commonly used criterion for distinguishing between these phases is that of the microlithic lunates, which were originally part of composite hunting tools (Bocquentin \& Bar-Yosef 2004; Yaroshevich et al. 2013). Larger lunates shaped by bifacial retouch, known as Helwan lunates, are typically attributed to the Early Natufian, whereas smaller backed lunates characterise the Late Natufian (e.g. Bar-Yosef \& Valla 1979; Valla 1984; Goring-Morris 1987). This chronological scheme is based upon the stratigraphic sequence of two major sites, Eynan and el-Wad Terrace (Garrod \& Bate 1937; Valla 1984; Kaufman et al. 2015), and is often used for determining the chronology of undated Natufian sites.

Natufian radiocarbon chronology is based on more than 120 radiocarbon dates, which supposedly represent the entire Natufian sequence (Maher et al. 2011: tab. 3; Grosman 2013: appendix). Many dates, however, are on materials from poorly defined contexts or were produced by old dating techniques, such as decay counting. Recent attempts to refine (C) Antiquity Publications Ltd, 2017 


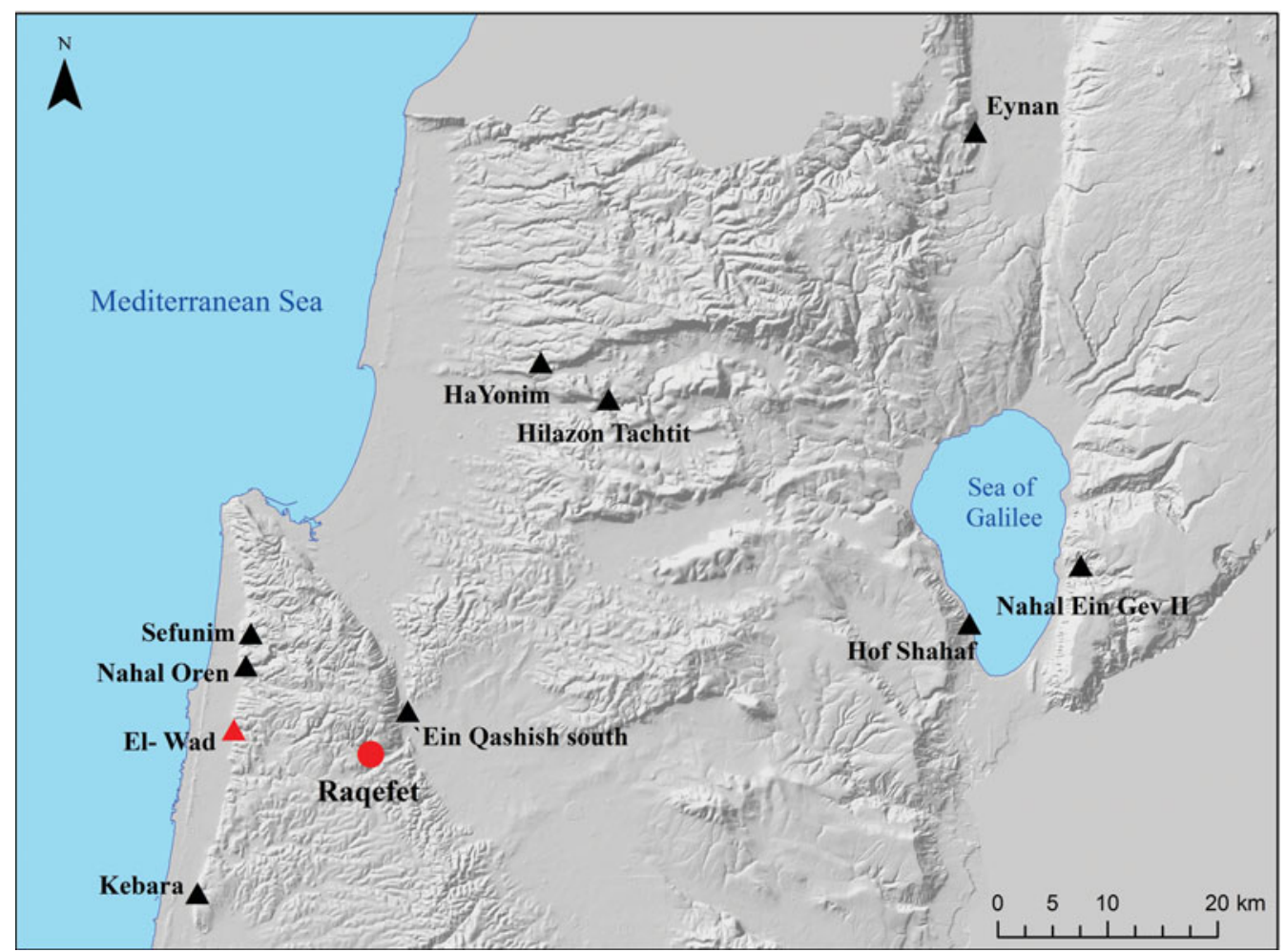

Figure 1. Map showing major Natufian sites in the Mediterranean core area of the Southern Levant. Raqefet Cave and el-Wad are marked in red.

the Natufian chronology based on published data applied several screening criteria to reduce uncertainties and errors. Maher et al. (2011: tab. 3), for example, excluded 34 published dates from their analysis that had large standard deviations or unclear archaeological contexts; single dates and old ${ }^{14} \mathrm{C}$ determinations were also excluded. Materials problematic for dating (e.g. burnt bones from the old excavations at Raqefet and Hatoula, or charcoal from old excavations at Jericho), however, were not excluded. Moreover, no control was applied regarding charcoal characteristics (i.e. old wood effect), and no details were provided on charcoal preservation.

The chronology proposed by Grosman (2013) relies on 23 dates attributed to the Early Natufian and 78 dates attributed to the Late Natufian. It is not specified which dates were excluded from the chronological scheme, but the database (Grosman 2013: appendix) is very similar to that of Maher et al. (2011: tab. 3). Dates were excluded from the analysis if they met one of three conditions: a) a large error range (more than 300 years); b) they were prepared before the beginning of the 1980s; or c) the age result is 2000 years older or younger than expected.

Blockley and Pinhasi (2011) rely solely on four Natufian sites for their chronology: Eynan, Hayonim, Nahal Oren (samples from not always clearly defined contexts) and Raqefet Cave (old excavation with unreliable contexts; see Lengyel 2007). In our view, 


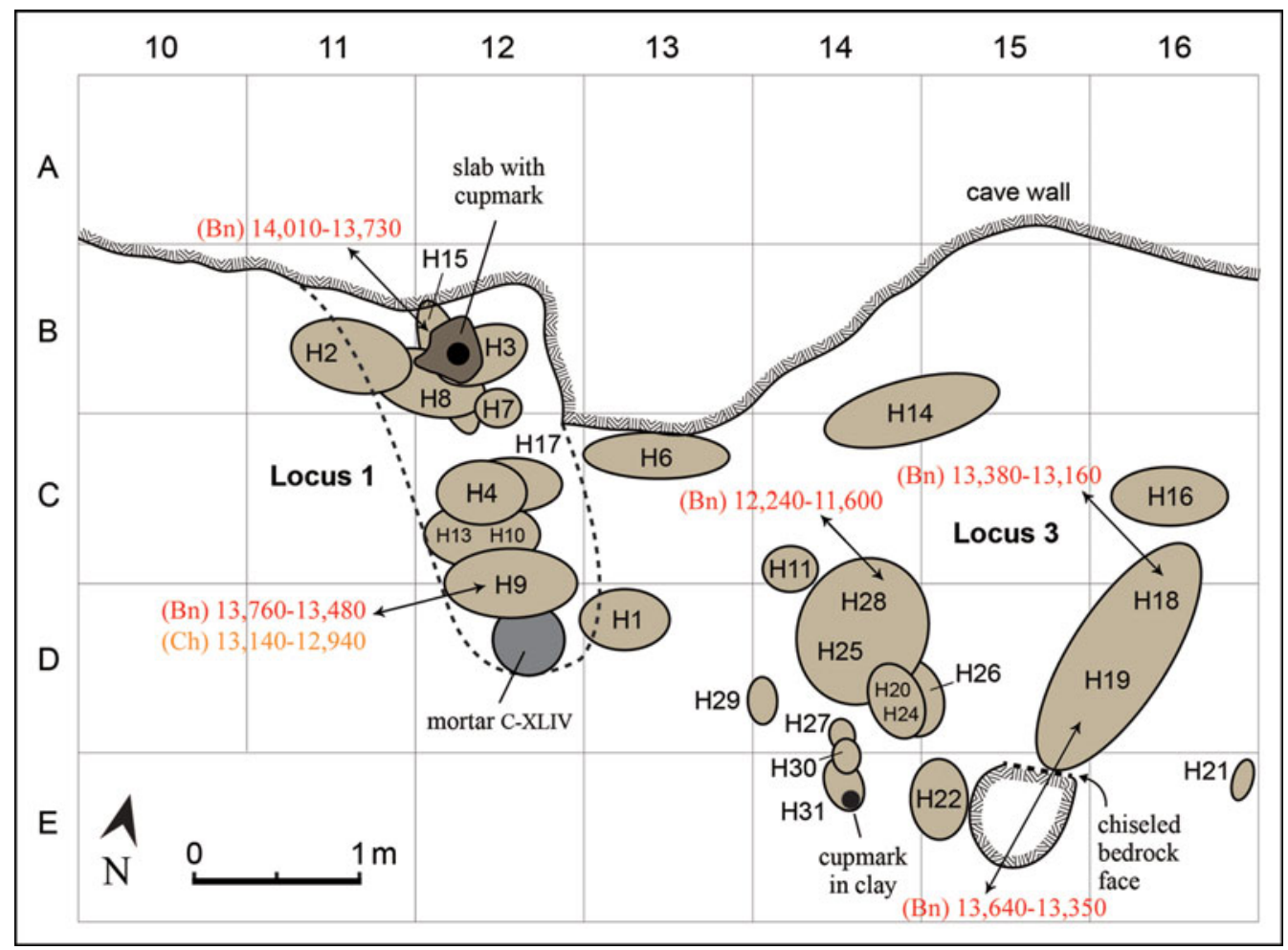

Figure 2. Plan of burials in the first chamber, Raqefet Cave. $B n=$ dated bone; $C h=$ dated charcoal.

this scheme, based exclusively on four sites, does not represent the entire range and nuances of the Natufian radiometric chronology.

To avoid such limitations, we chose to focus on recently produced dates from two nearby sites from Mount Carmel as a case study for Natufian chronology, which are from welldefined, high-quality contexts. Accordingly, we here present new dates obtained from the recent excavations at Raqefet Cave and compare them to the published dates from el-Wad Terrace (Eckmeier et al. 2012; Weinstein-Evron et al. 2012; Caracuta et al. 2016). The dates from these sites, excavated using similar modern methods, and with samples extracted from secure contexts, enable us to establish a radiometric chronological framework into which the lunate assemblages from these sites can be incorporated.

\section{Raqefet Cave}

Raqefet Cave is situated in an inner wadi (Raqefet) on the south-eastern side of Mount Carmel (Figure 1). The site was first excavated between 1970 and 1972 (Noy \& Higgs 1971). Renewed excavations from 2004-2011 (Nadel et al. 2008, 2009, 2012; Lengyel et al. 2013) revealed that the Natufians used the site primarily for burials, as evidenced by 29 adult, child and infant interments (Figures 2-5; Nadel et al. 2012). Four graves had direct (C) Antiquity Publications Ltd, 2017 


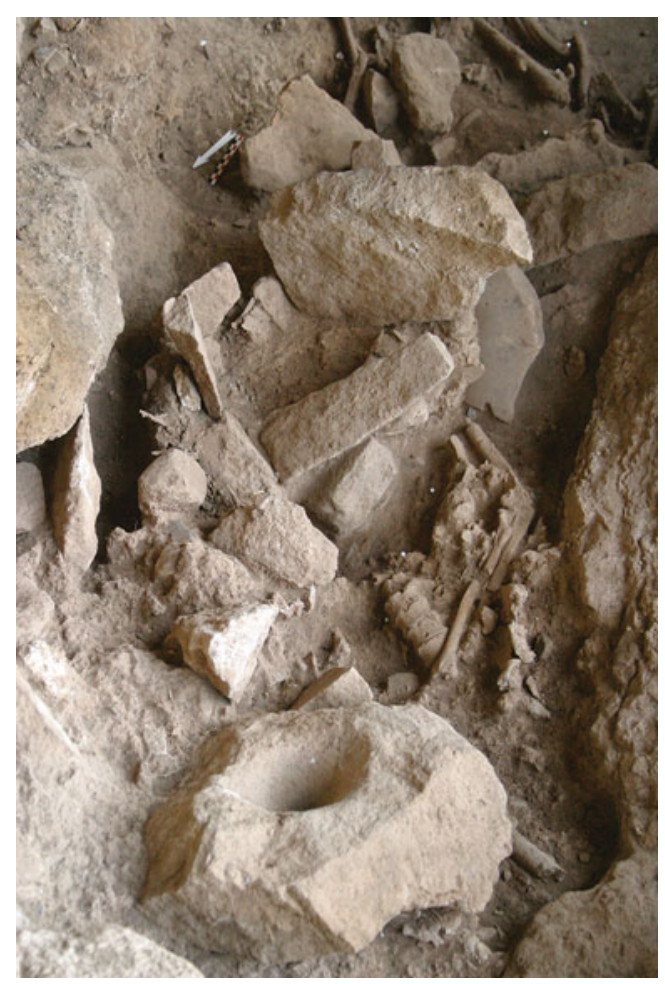

Figure 3. Locus 1 during excavation, looking south-east. Human bones of several individuals are visible. Note the use of stone objects, and the slab with a cupmark on top. evidence of a lining, composed of a thick layer of plant material, including sage flowers (Nadel et al. 2013).

A further aspect of note at the site is the wide variety of features hollowed out of the bedrock (Nadel \& Lengyel 2009; Nadel et al. 2015; Nadel \& Rosenberg 2016). Stones set on edge were found in a few of the larger, rock-cut mortars (or deep shafts), and phytoliths were recovered from several deep mortars (Power et al. 2014).

The flint assemblage contains over 20000 artefacts, and is currently undergoing detailed analyses (Nadel et al. 2008; Lengyel 2009; Lengyel et al. 2013). Two samples from the richest loci (1 and 3) were analysed as part of the current research (Table 1). This corpus of flints was recovered from the immediate surroundings of the burial pits or from within the graves, and should be viewed as representing the cemetery as a whole. In both loci, flakes are the dominant product, comprising just over 50 per cent of the total assemblages. Bladelets are approximately

four times more common than blades. Tools encompass 7.9 and 6.4 per cent of the lithic assemblages from loci 1 and 3 respectively. In these loci the lunate assemblage ( $\mathrm{n}=200)$ is dominated by the abruptly backed type (89.5 per cent). The abrupt category includes both unipolar and bipolar specimens, and a mixture of both (Figure 6). The Helwan lunates include fully and partially retouched specimens (Figure 7), and eight specimens that have both Helwan and some abrupt retouch. According to the commonly used relative Natufian chronology (e.g. Bar-Yosef \& Valla 1979; Valla 1984), this proportion of abruptly backed lunates aligns the Raqefet assemblage with the Late Natufian phase.

Comparing complete Helwan $(\mathrm{n}=12)$ and abruptly backed lunate $(\mathrm{n}=104)$ lengths shows that the former lunates are significantly larger than the latter $\left(t_{(114)}=-2.377, p=\right.$ 0.019) (Table 2).

Flint from the grave fills may not be directly associated with the dated human remains. Such lithics must be either contemporaneous or earlier to have been included in the burials. The relationship of the burials with the materials in the fills was, however, examined taphonomically in the study of the faunal remains from locus 1; these food remains were interpreted as representing funerary feasts, rather than domestic Natufian refuse accumulated prior to the digging of the graves (Yeshurun et al. 2013). 


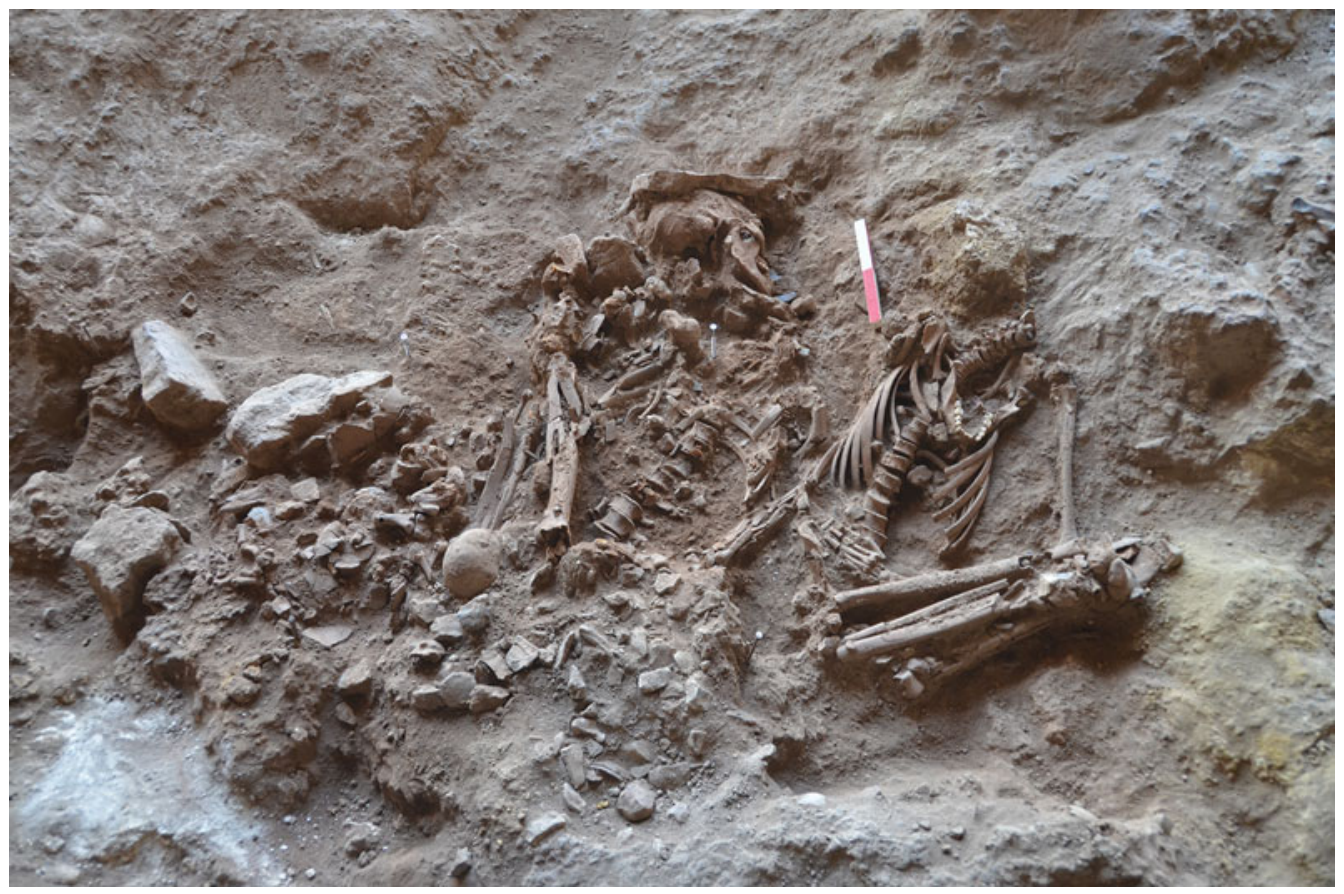

Figure 4. The double burial of Homo 25 and Homo 28.

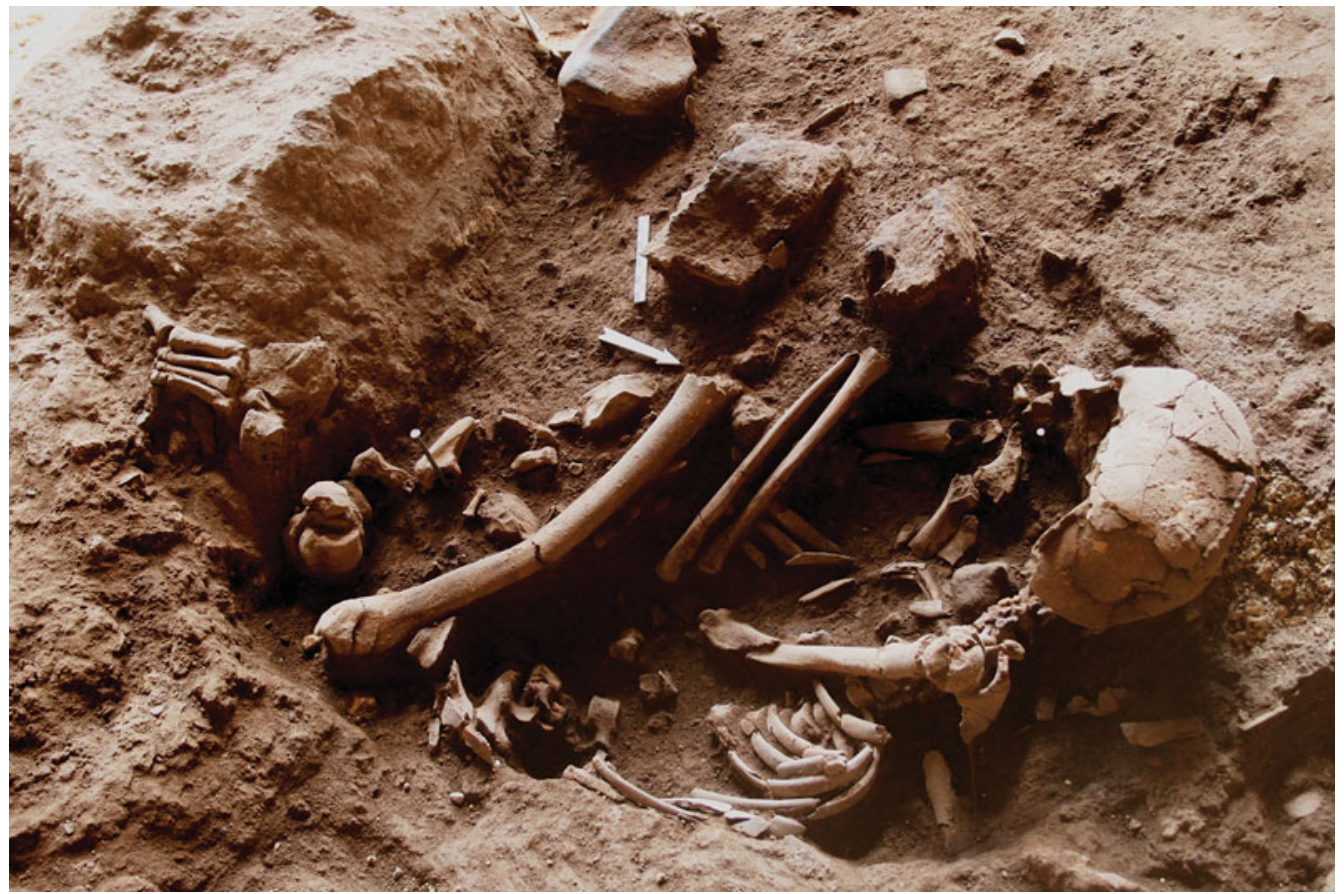

Figure 5. Homo 19 during excavation.

(C) Antiquity Publications Ltd, 2017 
Table 1. A breakdown of flint samples from loci 1 and 3 according to blanks (Raqefet Cave). Note the high similarity between the two loci.

\begin{tabular}{lccccc}
\hline & Blades & Bladelets & Flakes & Cores & Total \\
\hline Locus 1 & & & & & \\
Debitage & 84 & 439 & 749 & 88 & 1360 \\
Tools & 23 & 66 & 28 & - & 117 \\
Total & 107 & 505 & 777 & 88 & 1477 \\
$\%$ & $7.2 \%$ & $34.2 \%$ & $52.6 \%$ & $6 \%$ & $100 \%$ \\
Locus 3 & & & & & \\
Debitage & 108 & 400 & 857 & 35 & 1400 \\
Tools & 16 & 463 & 17 & - & 96 \\
Total & 124 & $30.9 \%$ & $58.4 \%$ & $2.3 \%$ & 1496 \\
$\%$ & $8.3 \%$ & & & & $100 \%$ \\
\hline
\end{tabular}

\section{The radiocarbon dates}

We obtained eight radiocarbon dates (see Table 3 for details) from Raqefet: five from human long bones belonging to five individuals (three adults and two adolescents), and three from charcoal pieces found in association with the burials.

The charcoal specimens were taxonomically identified and pre-treated following the standard water-acid-base-acid procedure that was also used for the el-Wad Terrace samples (Eckmeier et al. 2012). The five bones were pre-screened using Fourier transform infrared spectroscopy, which determined their splitting factor and the preservation of collagen (Rebollo et al. forthcoming). Sediments adhering to the bones were removed before prescreening and their mineralogical composition was analysed. Bone samples were prepared following the ultrafiltration method of Bronk Ramsey et al. (2004). Quality control of the suitability of the dated samples was carried out for each sample. All radiocarbon dates were calibrated using IntCal13 (Reimer et al. 2013) and OxCal v4.2 (Bronk Ramsey 2009). All samples were prepared and measured at the Dangoor Research Accelerator Mass Spectrometer D-REAMS for Radiocarbon Dating at the Weizmann Institute of Science.

The new set of dates from Raqefet Cave clusters between 14000 and $13000 \mathrm{cal} \mathrm{BP}$, except for RTK 6638, which dates to around $12000 \mathrm{cal} \mathrm{BP}$ (Figure 8). The stratigraphy, spatial distribution of the burials and radiocarbon dates indicate that the site was used as a Natufian burial ground over many generations. The earliest burial phase is locus 1 (Figure 3), which saw the burial of at least ten individuals between 14010 and 13480 years cal BP. This range is derived from the dating of the lowest burial in the northern cluster (Homo 15, RTK 6481) and the uppermost burial in the southern cluster (Homo 9, RTK 6541). These dates confirm the diachronic progression of the burials in the rock basin, starting from the north, adjacent to the wall of the cave, and continuing towards the south (Lengyel et al. 2013). Dating of charcoal from the southern cluster may extend the use of this location to 13 140-12940 year cal BP. The radiometric results show that this location was used for burial for approximately 500 years, and possibly more. 

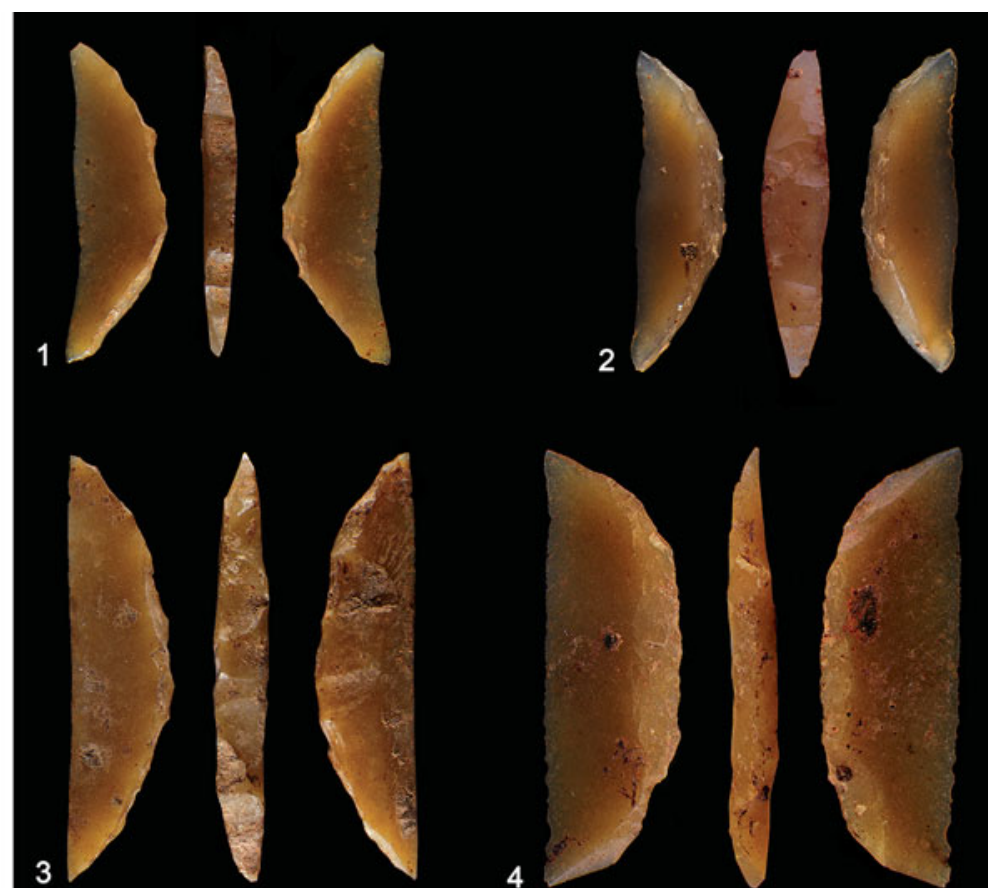

4
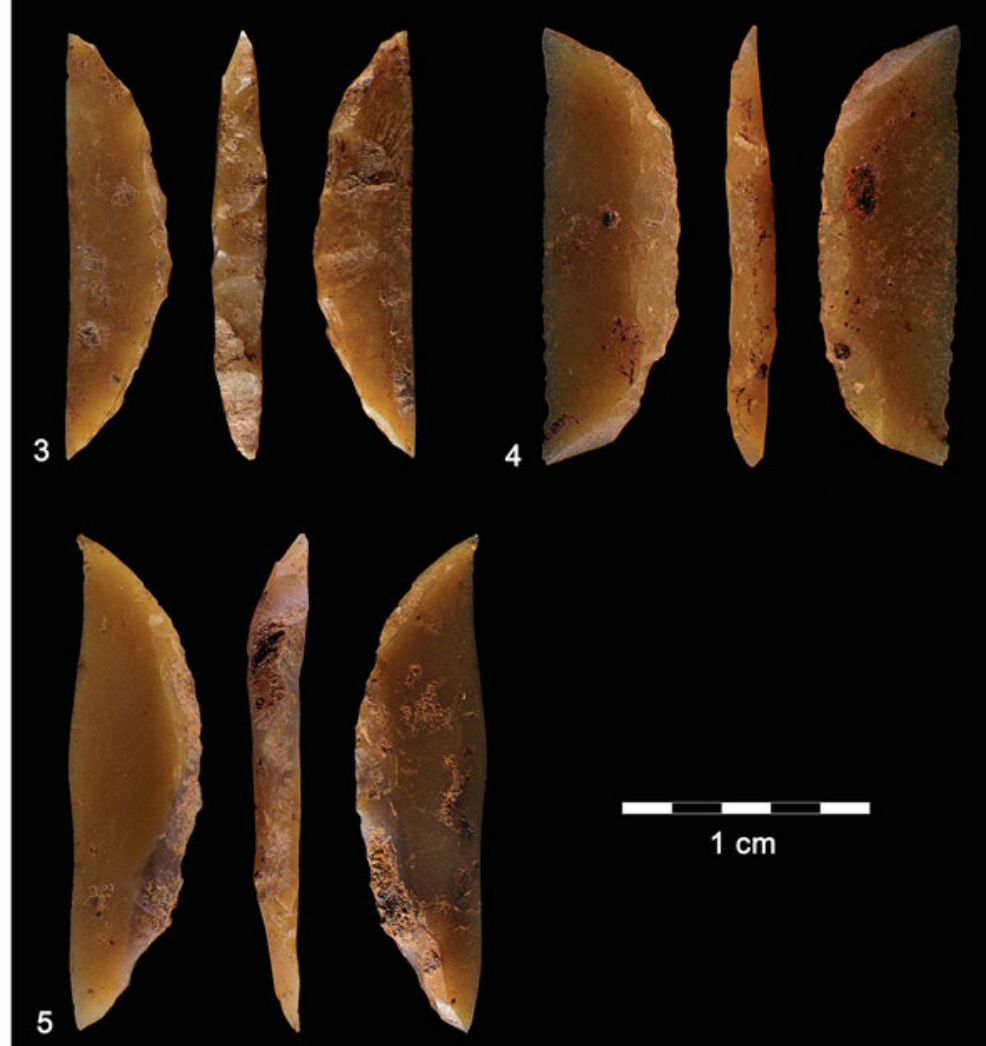

Figure 6. Lunates from Raqefet Cave. 1: Abrupt (locus 1, C12a, 222-228); 2: abrupt and bipolar (locus 3, 195-200); 3: bipolar (locus 3, C15d, 190-195); 4: Helwan (locus 3, E15a, 210-214); 5: Helwan and abrupt (locus 3, 193-200).

Other dated graves were double interments in the adjacent locus 3. The double grave containing Homo 18/Homo 19 was dated to 13640-13 $160 \mathrm{cal} \mathrm{BP}$ and the double grave of Homo 25/Homo 28 was dated to $12400-11600 \mathrm{cal} \mathrm{BP.}$

\section{Discussion}

Recent evaluations of available radiocarbon dates have proposed that the Natufian lasted approximately 3500 years, between c. 15000 and 11500 cal BP (e.g. Goring-Morris (C) Antiquity Publications Ltd, 2017 
Table 2. Dimensions (in $\mathrm{mm}$ ) of complete lunates from loci 1 and 3, according to type (Raqefet Cave).

\begin{tabular}{llccc}
\hline & & Length & Width & Thickness \\
\hline \multirow{3}{*}{ Abrupt } & & & & \\
& Mean & 15.54 & 4.9 & 2.16 \\
\multirow{3}{*}{ Helwan } & N & 104 & 104 & 104 \\
& Standard deviation & 3.32 & 1.29 & 0.52 \\
\multirow{3}{*}{ Total } & Mean & 17.9 & 4.91 & 1.96 \\
& N & 12 & 12 & 12 \\
& Standard deviation & 2.4 & 1.03 & 0.41 \\
& Mean & 15.79 & 4.9 & 2.14 \\
& N & 116 & 116 & 116 \\
& Standard deviation & 3.31 & 1.26 & 0.52 \\
\hline
\end{tabular}

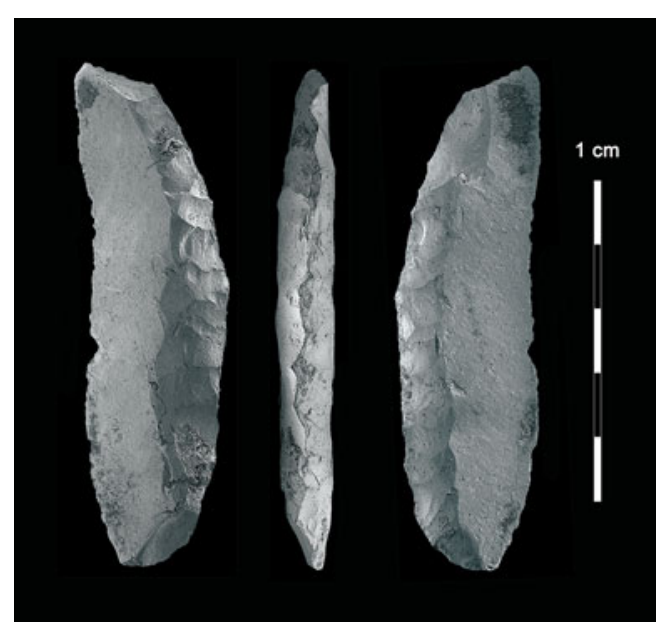

Figure 7. SEM image of a Helwan lunate (locus 1, B12d, 223-238). et al. 2009; Bar-Yosef 2011; Blockley \& Pinhasi 2011; Grosman 2013). This time span is usually further divided (mainly based on lithic typology) into two major phases: the Early and Late Natufian. The changeover is considered to have occurred at approximately $13500 \mathrm{cal} \mathrm{BP}$. Our new results from Raqefet Cave demonstrate that the postulated shift from Early to Late Natufian may have occurred earlier than previously suggested. The radiocarbon dates from the Raqefet Cave burials, in association with the proportion of backed lunates in the graves, sets the beginning of the Late Natufian at Mount Carmel to around $14000 \mathrm{cal} \mathrm{BP}$, if the two phases are defined by their lunate assemblages.

Consequently, the Late Natufian lithic assemblage at Raqefet Cave falls within the commonly accepted time range of the Early Natufian (Goring-Morris et al. 2009; Bar-Yosef 2011).

This chronology is supported by comparing the Raqefet Cave results to the neighbouring Natufian site of el-Wad Terrace, located $10 \mathrm{~km}$ to the west (Figure 1). El-Wad Terrace provides one of the most detailed and best-dated Natufian sequences in the Mediterranean core area (Weinstein-Evron et al. 2012; Kaufman et al. 2015). The Early Natufian at el-Wad Terrace is represented by a thick layer $(>1 \mathrm{~m})$ containing structures with living floors, and overlying occupation levels with no architecture. The lithic assemblage from the Early Natufian contexts is clearly dominated by large Helwan lunates (Kaufman et al. 2015).

Comparison between the lunate assemblages from Raqefet Cave and el-Wad Terrace shows differences between the sites. El-Wad Terrace units 1-2 and W0, which are the two uppermost Natufian levels, are the closest to Raqefet Cave in the Helwan: abrupt 
Table 3. ${ }^{14} \mathrm{C}$ dates from Raqefet Cave and el-Wad. The Raqefet Cave dates of Homo 18, 19 and 28 from Nadel et al. (2013), the el-Wad dates from Weinstein-Evron et al. (2012) and Caracuta et al. (2016). Eight samples from el-Wad were excluded from this table as they were either too old (RT 6097-2, RTD 6957 and RTD 6958) or their cultural context was not secure (RTT 6114, 6095-2) (Weinstein-Evron et al. 2012: 820-21).

\begin{tabular}{|c|c|c|c|c|c|c|c|}
\hline Site & Context & Period & $\begin{array}{l}\text { Sample } \\
\text { type }\end{array}$ & $\begin{array}{l}\text { Laboratory } \\
\text { number }\end{array}$ & $\begin{array}{c}{ }^{14} \mathrm{C} \text { age } \mathrm{BP} \\
(68.2 \% \\
\text { confidence })\end{array}$ & $\begin{array}{c}\text { Calibrated } \\
\text { range } \pm 1 \sigma \\
\text { year BP }\end{array}$ & $\begin{array}{c}\text { Calibrated } \\
\text { range } \pm 2 \sigma \\
\text { year BP }\end{array}$ \\
\hline Raqefet & Homo 28, L. 3 & $\mathrm{LN}$ & human bone & RTK 6638 & $10320 \pm 115$ & $\begin{array}{c}12400-11960(67.9 \%) \\
11860-11850(0.3 \%)\end{array}$ & $12550-11710(95.4 \%)$ \\
\hline Raqefet & Homo 9, L. 1 & $\mathrm{LN}$ & $\begin{array}{l}\text { charcoal } \\
\text { (Prunus) }\end{array}$ & RTK 6479 & $11155 \pm 70$ & $13100-12940(68.2 \%)$ & $13140-12820(95.4 \%)$ \\
\hline Raqefet & L. 3 & $\mathrm{LN}$ & $\begin{array}{l}\text { charcoal } \\
\text { (Prunus) }\end{array}$ & RTK 6798.1 & $11402 \pm 83$ & $13320-13140(68.2 \%)$ & $13410-13090(95.4 \%)$ \\
\hline Raqefet & Homo 18, L. 3 & $\mathrm{LN}$ & human bone & RTK 6607 & $11405 \pm 120$ & $13360-13130(68.2 \%)$ & $13470-13060(95.4 \%)$ \\
\hline Raqefet & Homo 19, L.3 & $\mathrm{LN}$ & human bone & $\begin{array}{l}\text { RTK } 6540 \\
\text { RTK } 6480 \\
\text { combine }\end{array}$ & $\begin{array}{l}11540 \pm 120 \\
11725 \pm 125 \\
\mathbf{1 1 6 3 0 \pm 8 7}\end{array}$ & $13560-13380(68.2 \%)$ & $\begin{array}{c}13710-13680(1.4 \%) \\
13620-13280(94 \%)\end{array}$ \\
\hline Raqefet & Homo 9, L. 1 & $\mathrm{LN}$ & human bone & RTK 6541 & $11790 \pm 125$ & $13740-13490(68.2 \%)$ & $13950-13380(95.4 \%)$ \\
\hline Raqefet & Homo 15, L. 1 & $\mathrm{LN}$ & human bone & RTK 6481 & $11995 \pm 125$ & $14030-13720(68.2 \%)$ & $14160-13560(95.4 \%)$ \\
\hline Raqefet & under Homo 26, L. 3 & $\mathrm{LN}$ & $\begin{array}{l}\text { charcoal } \\
\text { (Quercus) }\end{array}$ & RTK 6795.1 & $12056 \pm 86$ & $14000-13780(68.2 \%)$ & $14140-13740(95.4 \%)$ \\
\hline El-Wad & Unit Ib & $\mathrm{LN}$ & charcoal & RTD 6976 & $10140 \pm 45$ & $\begin{array}{c}11950-11870(22.5 \%) \\
11840-11700(42.8 \%) \\
11660-11650(2.9 \%)\end{array}$ & $\begin{array}{c}12030-11600(94.1 \%) \\
11520-11500(1.3 \%)\end{array}$ \\
\hline El-Wad & Unit Ib & $\mathrm{LN}$ & charcoal & RTD 6963 & $10295 \pm 45$ & $\begin{array}{c}12220-12220(1.9 \%) \\
12160-11970(66.3 \%)\end{array}$ & $\begin{array}{c}12380-12270(11 \%) \\
12240-11940(80.4 \%) \\
11880-11840(4 \%)\end{array}$ \\
\hline El-Wad & Unit I /II & $\mathrm{LN}$ & charcoal & RTD 6954 & $10460 \pm 45$ & $\begin{array}{c}12530-12380(55.4 \%) \\
12320-12310(3.5 \%) \\
12270-12240(9.3 \%)\end{array}$ & $12550-12140(95.4 \%)$ \\
\hline El-Wad & Unit I /II & $\mathrm{LN}$ & charcoal & RTD 6964 & $11150 \pm 60$ & $13100-12960(68.2 \%)$ & $13120-12830(95.4 \%)$ \\
\hline
\end{tabular}


Table 3. Continued.

\begin{tabular}{|c|c|c|c|c|c|c|c|c|}
\hline & Site & Context & Period & $\begin{array}{l}\text { Sample } \\
\text { type }\end{array}$ & $\begin{array}{l}\text { Laboratory } \\
\text { number }\end{array}$ & $\begin{array}{c}{ }^{14} \mathrm{C} \text { age } \mathrm{BP} \\
(68.2 \% \\
\text { confidence })\end{array}$ & $\begin{array}{c}\text { Calibrated } \\
\text { range } \pm 1 \sigma \\
\text { year BP }\end{array}$ & $\begin{array}{c}\text { Calibrated } \\
\text { range } \pm 2 \sigma \\
\text { year BP }\end{array}$ \\
\hline & El-Wad & Unit II & $\mathrm{LN}$ & charcoal & RTD 6955 & $11825 \pm 50$ & $13720-13590(68.2 \%)$ & $\begin{array}{c}13766-13540(95 \%) \\
13498-13490(0.4 \%)\end{array}$ \\
\hline & El-Wad & Unit II & EN & bone & RTT 5786 & $11370 \pm 115$ & $13310-13100(68.2 \%)$ & $13450-13040(95.4 \%)$ \\
\hline & El-Wad & Unit II & EN & charcoal & RTD 6959 & $11445 \pm 50$ & $13350-13220(68.2 \%)$ & $13410-13160(95.4 \%)$ \\
\hline & El-Wad & Unit II & EN & charcoal & RTD 6956 & $11460 \pm 45$ & $13370-13260(68.2 \%)$ & $13420-13200(95.4 \%)$ \\
\hline & El-Wad & Unit II & EN & bone & RTT 6115 & $11570 \pm 75$ & $13460-13320(68.2 \%)$ & $13560-13270(95.4 \%)$ \\
\hline & El-Wad & Unit II & EN & charcoal & RTT 6116 & $11640 \pm 70$ & $13550-13410(68.2 \%)$ & $13590-13300(95.4 \%)$ \\
\hline & El-Wad & Unit II & EN & charcoal & RTT 6106 & $11840 \pm 100$ & $13760-13560(68.2 \%)$ & $\begin{array}{c}13940-13890(2.9 \%) \\
13860-13460(92.5 \%)\end{array}$ \\
\hline & El-Wad & Unit II & EN & charcoal & RTT 6105 & $11935 \pm 100$ & $\begin{array}{c}13930-13900(5.7 \%) \\
13860-13600(62.5 \%)\end{array}$ & $14050-13550(95.4 \%)$ \\
\hline & El-Wad & Unit II & EN & bone & RTT 5790 & $11965 \pm 125$ & $\begin{array}{c}13990-13710(61.8 \%) \\
13670-13630(6.4 \%)\end{array}$ & $\begin{array}{c}14130-13540(95.1 \%) \\
13500-13500(0.3 \%)\end{array}$ \\
\hline & El-Wad & Unit II & EN & charcoal & RTD 6975 & $12140 \pm 50$ & $14110-13940(68.2 \%)$ & $14160-13820(95.4 \%)$ \\
\hline & El-Wad & Unit II & EN & charcoal & RTT 6117-2 & $12300 \pm 70$ & $14420-14090(68.2 \%)$ & $14690-14030(95.4 \%)$ \\
\hline & El-Wad & Unit II & EN & charcoal & RTT 6096-2 & $12340 \pm 85$ & $14560-14140(68.2 \%)$ & $14840-14050$ (95.4\%) \\
\hline (2) & El-Wad & Unit II & EN & charcoal & RTD 6960 & $12350 \pm 50$ & $14490-14160(68.2 \%)$ & $14700-14110(95.4 \%)$ \\
\hline$\vec{B}$ & El-Wad & Unit II & EN & bone & RTT 6107 & $12350 \pm 100$ & $14620-14150(68.2 \%)$ & $14930-14040(95.4 \%)$ \\
\hline . & El-Wad & Unit II & EN & charcoal & RTT 6098-2 & $12430 \pm 80$ & $14750-14280(68.2 \%)$ & $14990-14160(95.4 \%)$ \\
\hline E. & El-Wad & Unit II & EN & human bone & RTT 6114 & $11570 \pm 75$ & $13460-13320(68.2 \%)$ & $13560-13270(95.4 \%)$ \\
\hline 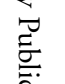 & El-Wad & Unit II & EN & charcoal & RTT 6095-2 & $11610 \pm 80$ & $\begin{array}{c}13540-13510(9.3 \%) \\
13490-13350(58.9 \%)\end{array}$ & $13582-13280(95.4 \%)$ \\
\hline$\cong$. & El-Wad & Unit II & EN & charcoal & RTT 6097-2 & $14150 \pm 140$ & $17440-17025(68.2 \%)$ & $17610-16760(95.4 \%)$ \\
\hline$\stackrel{0}{\circ}$ & El-Wad & Unit II & EN & charcoal & RTD 6957 & $14266 \pm 55$ & $17490-17270(68.2 \%)$ & $17570-17160(95.4 \%)$ \\
\hline$\stackrel{n}{5}$ & El-Wad & Unit II & EN & charcoal & RTD 6958 & $15350 \pm 60$ & $18710-18560(68.2 \%)$ & 18 770-18 $480(95.4 \%)$ \\
\hline
\end{tabular}

\section{Research}


OxCal v4.2.4 Bronk Ramsey (2013); r.5 IntCal13 atmospheric curve (Reimer et al 2013)

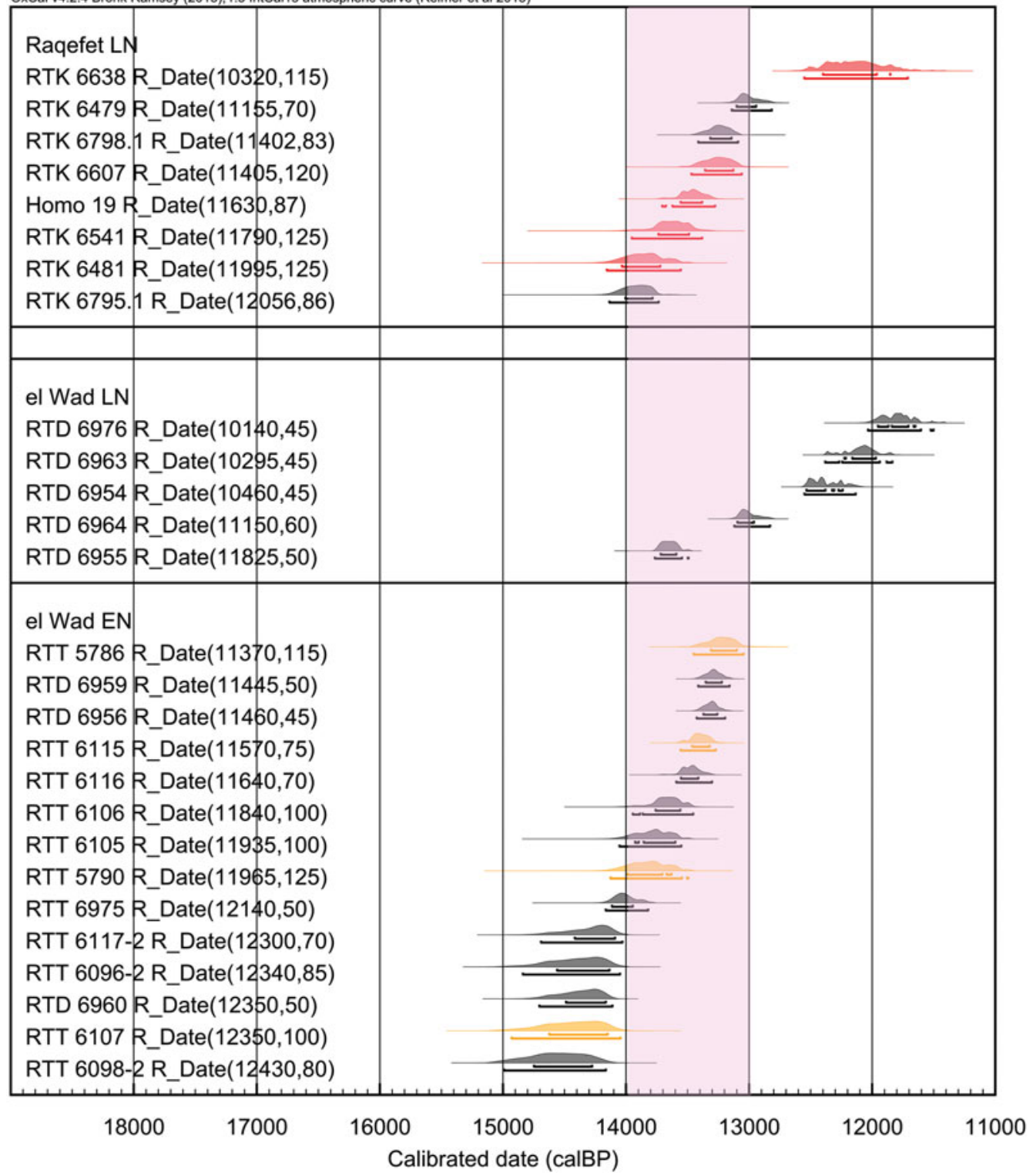

Figure 8. Probability distribution of the calibrated radiocarbon dates from Raqefet Cave and el-Wad Terrace. Colour codes refer to material type: red: human bone; orange: animal bone; black: charcoal.

ratio. The latter, however, has a higher proportion (almost 25 per cent) of backed lunates (Table 4). Hierarchical cluster analysis of the proportions of the two types of lunates in each assemblage shows two groups (Figure 9). The smaller group includes Raqefet Cave and el-Wad units 1-2 and W0; the rest of the el-Wad assemblages comprise the larger group.

(C) Antiquity Publications Ltd, 2017 
Table 4. Frequencies of Helwan and backed lunates along the el-Wad sequence (Kaufman et al. 2015).

\begin{tabular}{llccc}
\hline & & Lunate types & & \\
& & Backed & Helwan & Total \\
& & & & \\
Raqefet & count & 179 & 21 & 200 \\
& \% within assemblage & 89.5 & 10.5 & 100 \\
El-Wad Unit 1-2 & count & 83 & 34 & 117 \\
& \% within assemblage & 70.9 & 29.1 & 100 \\
El-Wad W0 & count & 62 & 35 & 97 \\
& \%within assemblage & 63.9 & 36.1 & 100 \\
El-Wad W1 & count & 8 & 13 & 21 \\
& \%within assemblage & 38.1 & 61.9 & 100 \\
El-Wad W2 & count & 32 & 39 & 71 \\
& \%within assemblage & 45.1 & 54.9 & 100 \\
El-Wad W3 & count & 10 & 29 & 39 \\
& \%within assemblage & 25.6 & 74.4 & 100 \\
El-Wad W4 & count & 21 & 42 & 63 \\
& \%within assemblage & 33.3 & 66.7 & 100 \\
El-Wad W5 & count & 51 & 131 & 182 \\
& \%within assemblage & 28 & 72 & 100 \\
El-Wad W6 & count & 73 & 210 & 283 \\
& \%within assemblage & 25.8 & 74.2 & 100 \\
El-Wad W7 & count & 27 & 59 & 86 \\
& \%within assemblage & 31.4 & 68.6 & 100 \\
Total & count & 463 & 579 & 1042 \\
& \% within assemblage & 44.4 & 55.6 & 100 \\
\hline
\end{tabular}

The el-Wad phases were recently radiocarbon dated and clearly show a continuous occupation for the Early Natufian between 15000 and $13200 \mathrm{cal} \mathrm{BP}$ (Figure 7) (Eckmeier et al. 2012; Weinstein-Evron et al. 2012). Evidence for the Late Natufian is sparse and dates to 13700-11 $800 \mathrm{cal}$ BP. The early age of sample RTK-6955 (charcoal) at el-Wad shows overlap there between the Early and the Late Natufian. Being a single date, it was, however, suspected to be an outlier. Now, the new Late Natufian dates from Raqefet Cave suggest the RTK-6955 sample is not an outlier. A comparison between the absolute chronology of Raqefet Cave and the Early Natufian absolute chronology of el-Wad shows an overlap of approximately 1000 years, between around 14000 and $13000 \mathrm{cal}$ BP. Thus, the latest Early Natufian of el-Wad Terrace and the earliest Late Natufian of Raqefet Cave are contemporaneous.

The well-established dating results from these two sites raise a question concerning the differences between the contemporaneous lithic assemblages. The distinct lunate compositions (in terms of type frequencies and dimensions) from the two sites are apparently synchronous and thus they cannot be interpreted as reflecting chronological phases. Similarity in ecological setting (e.g. Caracuta et al. 2016) and the limited geographic distance between the sites would seem to exclude the possibility that the two communities did not interact. One plausible explanation for the typological difference is that there was a long intermediate phase between the Early and the Late Natufian during which the two 
Omry Barzilai et al.

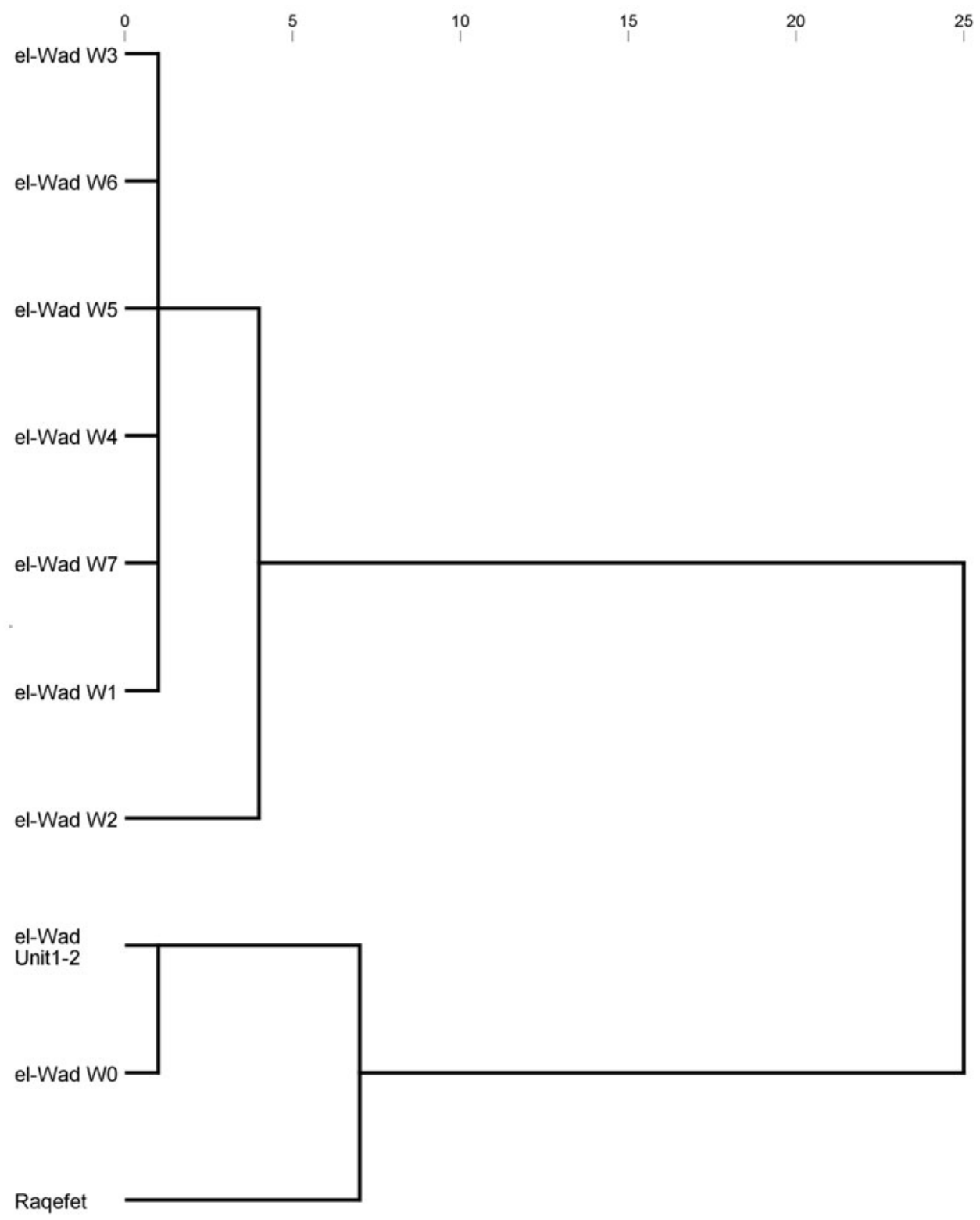

Figure 9. Hierarchical cluster analysis of Raqefet Cave and el-Wad Terrace using the proportions of abruptly backed and Helwan lunates.

lunate types coexisted (Kaufman et al. 2015). Although the presence of the two types together in Natufian sites has usually been interpreted as a mixture of two chronological phases, this a priori assumption has been questioned for several sites in the southern Levant (Olszewski 1986, 1988; Barzilai et al. 2015). The use of lunates as a relative chronological marker has been further challenged by the discovery of small lunates modified by Helwan (C) Antiquity Publications Ltd, 2017 
retouch at the open-air sites of Hof Shahaf and Shubayqa 1 (Marder et al. 2013; Richter et al. 2014). Their position within Natufian chronology is currently unknown due to the lack of radiocarbon dating.

Another explanation for the typological differences between Raqefet Cave and el-Wad Terrace may be found in the social sphere. Ethnographic studies show that projectile style can convey social information (e.g. Wiessner 1983). Thus, it is possible that the typological differences in lunate types, commonly used as projectiles (Yaroshevich et al. 2013), may attest to social identity. Raqefet Cave functioned primarily as a Natufian burial ground, whereas el-Wad Terrace was a settlement including dwellings, burials and a variety of features (Garrod \& Bate 1937; Weinstein-Evron 1998, 2009). That no settlement evidence was found at Raqefet Cave (Nadel et al. 2008, 2009, 2012, 2013) suggests that the site must have been used as a burial place for a Natufian settlement nearby. The difference between the lunate assemblages at Raqefet Cave and el-Wad, as well as the presence of burials at el-Wad, suggest that the former was not the burial site of the latter. Thus it is possible that the Raqefet Cave cemetery represents a geographic marker that distinguished between two co-existing Natufian communities, each with its different lithic tradition (i.e. lunate types) within Mount Carmel and maybe also the valleys to the east.

The current case study highlights a common archaeological problem: namely, the integration of relative and absolute chronologies. Natufian sites in the Mediterranean woodland zone are stratigraphically complex and include archaeological contexts that were subjected to a variety of taphonomic processes. It is crucial, therefore, to retrieve materials for absolute and relative dating (e.g. radiocarbon and lithic typologies) from the same secure contexts, such as graves and living floors. Our study shows that the Raqefet Cave cemetery was used for many centuries and that the fossil directeur of the Natufian, the lunate, is not a suitable chronological marker in the Mount Carmel region for the period between 14000 and $13000 \mathrm{cal} \mathrm{BP}$.

Our results therefore question the reliability of the commonly used lunate-based relative dating of the Natufian. This applies to the Mediterranean zone, but may have implications for other regions. Hence the use of tool types as a proxy for dating Natufian phases (and probably also phases in other periods and places) should not be considered sufficient to support a high-precision chronology. Furthermore, only specimens retrieved from secure contexts should be incorporated in such relative dating schemes, and wherever possible they should be compared to context-specific radiocarbon dates. It is hoped that additional case studies will enhance the resolution of our dating of the Natufian, and thus further illuminate the complex processes that led to the establishment of sedentary communities and the development of agriculture in the Near East.

\section{Acknowledgements}

This work forms part of a post-doctoral research project conducted by O.B., supervised by E.B. (ISF grant 475/10). Fieldwork was carried out under licence numbers G-2004/50, G-34/2006, G-64/2008, G-34/2010 and G-22/2011 of the Israel Antiquities Authority, and permits of the Israel Nature and Parks Authority. The Irene Levi-Sala CARE Archaeological Foundation, the National Geographic Society (grant 8915-11) and the Wenner-Gren Foundation (grant 7481-2008) generously supported the excavation. Teresa Cabellos Panades, Aurore Lambert and Gabrielle Bosset assisted in the excavation of the burials. Michal Birkenfeld prepared Figure 1. Anat Regev-Gisis prepared Figures 2, 6 and 7. We thank N. Taha from the Basin Analysis and 
Petrophysical laboratory (PetroLab) at the University of Haifa, and N. Waldmann and R. Reshef for their help in documenting the lunates. E. Gershtein prepared the photographs of lunates.

\section{References}

Bar-Oz, G., R. Yeshurun \& M. Weinstein-Evron. 2013. Specialized hunting of gazelle in the Natufian: cultural cause or climatic effect?, in O. Bar-Yosef \& F.R. Valla (ed.) Natufian foragers in the Levant: Terminal Pleistocene social changes in western Asia: 685-98. Ann Arbor (MI): International Monographs in Prehistory.

Bar-Yosef, O. 2011. Climatic fluctuations and early farming in West and East Asia. Current Anthropology 52(4): S175-93. https://doi.org/10.1086/659784

Bar-Yosef, O. \& F.R. Valla. 1979. L'évolution du Natufien, nouvelles suggestions. Paléorient 5: 145-52. https://doi.org/10.3406/paleo.1979.4243

Barzilai, O., N. Agha, H. Ashkenazy, M. Birkenfeld, E. Boaretto, N. Porat, P. Spivak \& J. Roskin. 2015. The Natufian site of Nahal Sekher VI: the 2009 excavation season. Mitekufat Haeven-Journal of the Israel Prehistoric Society 45: $22-72$.

Belfer-Cohen, A. 1988. The Natufian settlement at Hayonim Cave: a hunter-gatherer band on the threshold of agriculture. Unpublished PhD dissertation, the Hebrew University of Jerusalem.

- 1991. The Natufian in the Levant. Annual Review of Anthropology 20: 167-86.

Belfer-Cohen, A. \& O. Bar-Yosef. 2000. Early sedentism in the Near East - a bumpy ride to village life, in I. Kuijt (ed.) Life in Neolithic farming communities. Social organization, identity, and differentiation: 19-38. New York: Kluwer Academic.

Belfer-Cohen, A. \& A.N. Goring-Morris. 2013. Breaking the mold: phases and facies in the Natufian of the Mediterranean zone, in O. Bar-Yosef \& F.R. Valla (ed.) Natufian foragers in the Levant: Terminal Pleistocene social changes in Western Asia: 544-61. Ann Arbor (MI): International Monographs in Prehistory.

Blockley, S.P.E. \& R. Pinhasi. 2011. A revised chronology for the adoption of agriculture in the southern Levant and the role of late glacial climatic change. Quaternary Science Reviews 30: 98-108. https://doi.org/10.1016/j.quascirev.2010.09.021

Bocquentin, F. 2003. Burial practices, biological factors and cultural identities during the Natufian period: a bio-archaeological perspective. Unpublished PhD dissertation, Université Bordeaux 1 (in French).
Bocquentin, F. \& O. Bar-Yosef. 2004. Early Natufian remains: evidence for physical conflict from $\mathrm{Mt}$ Carmel, Israel. Journal of Human Evolution 47: 19-23. https://doi.org/10.1016/ j.jhevol.2004.05.003

Bronk Ramsey, C. 2009. Bayesian analysis of radiocarbon dates. Radiocarbon 51: 337-60. https://doi.org/10.1017/S0033822200033865

Bronk-Ramsey, C., T. Higham, A. Bowles \& R. Hedges. 2004. Improvements to the pretreatment of bone at Oxford. Radiocarbon 46: 155-63. https://doi.org/10.1017/ S0033822200039473

Byrd, B.F. \& C.F. Monahan. 1995. Death, mortuary ritual, and Natufian social structure. Journal of Anthropological Archaeology 14: 251-87. https://doi.org/10.1006/jaar.1995.1014

Caracuta, V., M. Weinstein-Evron, R. Yeshurun, D. Kaufman, A. Tsatskin \& E. Boaretto. 2016. Charred wood remains in the Natufian sequence of el-Wad Terrace (Israel): new insights into the climatic, environmental and cultural changes at the end of the Pleistocene. Quaternary Science Reviews 131: 20-32. https://doi.org/10.1016/ j.quascirev.2015.10.034

Davis, S.J.M. \& F.R. Valla. 1978. Evidences for the domestication of the dog in the Natufian of Israel 12,000 years ago. Nature 276: 608-10. https://doi.org/10.1038/276608a0

Dubreuil, L. 2004. Long-term trends in Natufian subsistence: a use-wear analysis of ground stone tools. Journal of Archaeological Science 31: 1613-29. https://doi.org/10.1016/ j.jas.2004.04.003

Eckmeier, E., R. Yeshurun, M. Weinstein-Evron, E. Mintz \& E. Boaretto. 2012. Radiocarbon dating of the Early Natufian at el-Wad Terrace, Mount Carmel, Israel: methodology and materials characterization. Radiocarbon 54: 823-36. https://doi.org/10.1017/S0033822200047470

EDwards, P.C. 2006. A 14000 year-old hunter-gatherer's toolkit. Antiquity 81: 865-76. https://doi.org/10.1017/S0003598X0009596X

Garrod, D.A.E. \& D.M.A. Bate. 1937. The Stone Age of Mount Carmel. Volume I. Excavations at the Wadi Mughara. Oxford: Clarendon.

Goring-Morris, A.N. 1987. At the edge: Terminal Pleistocene hunter-gatherers in the Negev and Sinai (British Archaeological Reports international series 361). Oxford: British Archaeological Reports. 


\section{Radiocarbon dating of human burials from Raqefet Cave}

Goring-Morris, A.N. \& A. Belfer-Cohen. 2013. Ruminations on the role of periphery and centre in the Natufian, in O. Bar-Yosef \& F.R. Valla (ed.) Natufian foragers in the Levant: Terminal Pleistocene social changes in Western Asia: 562-83. Ann Arbor (MI): International Monographs in Prehistory.

Goring-Morris, A.N., E. Hovers \& A. Belfer-Cohen. 2009. The dynamics of Pleistocene settlement patterns and human adaptations in the Levant-an overview, in J.J. Shea \& D. Lieberman (ed.) Transitions in prehistory: papers in honor of Ofer Bar-Yosef: 187-254. Oakville (CT): David Brown \& Oxbow.

Grosman, L. 2013. The Natufian chronological scheme-new insights and their implications, in O. Bar-Yosef \& F.R. Valla (ed.) Natufian foragers in the Levant: Terminal Pleistocene social changes in Western Asia: 622-37. Ann Arbor (MI): International Monographs in Prehistory.

Grosman, L., N.D. Munro \& A. Belfer-Cohen. 2008. A 12,000-year-old shaman burial from the southern Levant (Israel). Proceedings of the National Academy of Sciences of the USA 105: 17665-69. https://doi.org/10.1073/pnas.0806030105

Kaufman, D., R. Yeshurun \& M. Weinstein-Evron. 2015. The Natufian sequence of el-Wad Terrace: seriating the lunates. Journal of the Israel Prehistoric Society 45: 143-57.

Lengyel, G. 2007. Upper Palaeolithic and Epipalaeolithic lithic technologies at Raqefet Cave, Mount Carmel East, Israel (British Archaeological Reports international series S1681). Oxford: Archaeopress.

- 2009. Operational schemas in the Upper Palaeolithic and Epipalaeolithic of Raqefet Cave. Analele Universitătii din Oradea, Seria Istorie-Arheologie 19: 5-12.

Lengyel, G., D. Nadel \& F. Bocquentin. 2013. The Natufian at Raqefet Cave, in O. Bar-Yosef \& F.R. Valla (ed.) Natufian foragers in the Levant: Terminal Pleistocene social changes in Western Asia: 478-504. Ann Arbor (MI): International Monographs in Prehistory.

Maher, L., E.B. Banning \& M. Chazan. 2011. Oasis or mirage? Assessing the role of abrupt climate change in the prehistory of the southern Levant. Cambridge Archaeological Journal 21: 1-29. https://doi.org/10.1017/S0959774311000011

Marder, O., R. Yeshurun, H. Smithline, O. Ackermann, D.E. Bar-Yosef Mayer, A. Belfer-Cohen, L. Grosman, I. Hershkovitz, N. Klein \& L. Weissbrod. 2013. Hof Shahaf: a new Natufian site on the shore of Lake Kinneret, in O. Bar-Yosef \& F.R. Valla (ed.) Natufian foragers in the Levant: Terminal Pleistocene social changes in western Asia: 505-26. Ann Arbor (MI): International Monographs in Prehistory.
Munro, N.D. 2004. Zooarchaeological measures of hunting pressure and occupation intensity in the Natufian. Current Anthropology 45: S5-34. https://doi.org/10.1086/422084

Nadel, D. \& G. Lengyel. 2009. Human-made bedrock holes (mortars and cupmarks) as a Late Natufian social phenomenon. Archaeology, Anthropology and Ethnology in Eurasia 37: 37-48. https://doi.org/10.1016/j.aeae.2009.08.012

Nadel, D. \& D. Rosenberg. 2016. An incised pattern inside a Raqefet Cave bedrock mortar: new dimensions to Natufian stone carvings. Journal of Lithic Studies 3: 337-57. https://doi.org/10.2218/jls.v3i3.1467

Nadel, D., G. Lengyel, F. Bocquentin, A. Tsatskin, D. Rosenberg, R. Yeshurun, G. Bar-Oz, D.E. Bar-Yosef Mayer, R. Beeri, L. Conyers, S. Filin, I. Hershkovitz, A. Kurzawska \& L. Weissbrod. 2008. Raqefet Cave: the 2006 excavation season. Journal of the Israel Prehistoric Society 38: 59-131.

Nadel, D., G. Lengyel, T. Cabellos, F. Bocquentin, D. Rosenberg, R. Yeshurun,

R. Brown-Goodman, A. Tsatskin, G. Bar-Oz \& S. Filin. 2009. The Raqefet Cave 2008 excavation season. Journal of the Israel Prehistoric Society 39: 21-61.

Nadel, D., A. Lambert, G. Bosset, F. Bocquentin, D. Rosenberg, R. Yeshurun, L. Weissbrod, A. Tsatskin, N. Bachrach, M. Bar-Matthews, A. Ayalon, Y. Zaidner, R. Beeri \& H. Grinberg. 2012. The 2010 and 2011 seasons of excavation at Raqefet Cave. Journal of the Israel Prehistoric Society 42: 35-73.

Nadel, D., A. Danin, R.C. Power, A. Rosen, F. Bocquentin, A. Tsatskin, D. Rosenberg, R. Yeshurun, L. Weissbrod, N.R. Rebollo, O. BARZILAi \& E. BoARETTO. 2013. Earliest floral grave lining from 13,700-11,700-y-old Natufian burials at Raqefet Cave, Mt Carmel, Israel. Proceedings of the National Academy of Sciences of the USA 110: 11774-78. https://doi.org/ 10.1073/pnas. 1302277110

Nadel, D., S. Filin, D. Rosenberg \& V. Miller. 2015. Prehistoric bedrock features: recent advances in 3D characterization and geometrical analyses. Journal of Archaeological Science 53: 331-34. https://doi.org/10.1016/j.jas.2014.10.029

Noy, T. \& E.S. Higgs. 1971. Raqefet Cave. Israel Exploration Journal 21: 225-26.

Olszewski, D.I. 1986. A reassessment of average lunate length as a chronological marker. Paléorient 12: 39-44. https://doi.org/10.3406/paleo.1986.4396

- 1988. The north Syrian Late Epipalaeolithic and its relationship to the Natufian Complex. Levant 20: 127-37. https://doi.org/10.1179/ lev.1988.20.1.127 
Power, R.C., A.M. Rosen \& D. Nadel. 2014. The economic and ritual utilization of plants at the Raqefet Cave Natufian site: the evidence from phytoliths. Journal of Anthropological Archaeology 33: 49-65. https://doi.org/ 10.1016/j.jaa.2013.11.002

Rebollo, N.R., O. Barzilai, F. Bocquentin, R. Yeshurun, Y. Asscher, D. Nadel \& E. BoAretto. Forthcoming. Mineralogical and compositional differences in diagenesis between animal and human bones: preservation study in Raqefet Cave.

Reimer, P.J., E. Bard, A. Bayliss, J.W. Beck, P.G. Blackwell, C. Bronk Ramsey, C.E. Buck, H. Cheng, R.L. Edwards, M. Friedrich, P.M. Grootes, T.P. Guilderson, H. Haflidason, I. Hajdas, C. Hatté, T.J. Heaton, D.L. Hoffmann, A.G. Hogg, K.A. Hughen, K.F. Kaiser, B. Kromer, S.W. Manning, M. Niu, R.W. Reimer, D.A. Richards, E.M. Scott, J.R. Southon, R.A. Staff, C.S.M. Turney \& J. van DER Plicht. 2013. IntCal13 and Marine13 radiocarbon age calibration curves $0-50,000$ years cal BP. Radiocarbon 55: 1869-87. https://doi.org/10.2458/azu_js_rc.55.16947

Richter, T., A. Arranz, M. House, A.M. Rafaiah \& L. Yeomans. 2014. Preliminary report on the second season of excavation at Shubayqa 1. Neo-Lithics 1: 3-10.

Rosenberg, D. \& D. Nadel. 2014. The sounds of pounding: boulder mortars and their significance to Natufian burial customs. Current Anthropology 55: 784-812. https://doi.org/10.1086/679287

Unger-Hamilton, R. 1991. Natufian plant husbandry in the southern Levant and comparison with that of the Neolithic periods: the lithic perspective, in O. Bar-Yosef \& F.R Valla (ed.) The Natufian culture in the Levant: 483-520. Ann Arbor (MI): International Monographs in Prehistory.
VAlla, F.R. 1984. Les industries de silex de Mallaha (Eynan) et du Natoufien dans le Levant (Mémoires et Travaux du Centre de Recherches Préhistoriques Françaises de Jerusalem 3). Paris: Association Paléorient.

- 1988. Aspects du sol de l'abri 131 de Mallaha (Eynan). Paléorient 14: 283-96. https://doi.org/10.3406/paleo.1988.4475

- 1995. The first settled societies-Natufian (12,500-10,200 BP), in T.E. Levy (ed.) The archaeology of society in the Holy Land: 170-87. London: Leicester University Press.

Weinstein-Evron, M. 1998. Early Natufian el-Wad revisited (Études et Recherches Archeologiques de l'Université de Liège 77). Liège: Université de Liège.

- 2009. Archaeology in the archives: unveiling the Natufian culture of Mount Carmel. Boston (MA): Brill \& American School of Prehistoric Research.

Weinstein-Evron, M., R. Yeshurun, D. Kaufman, E. Eckmeier \& E. BoAretto. 2012. New ${ }^{14} \mathrm{C}$ dates for the early Natufian of el-Wad Terrace, Mount Carmel, Israel. Radiocarbon 54: 813-22. https://doi.org/10.1017/S0033822200047469

Wiessner, P. 1983. Style and social information in Kalahari San projectile points. American Antiquity 48: 253-76. https://doi.org/10.2307/280450

Yaroshevich, A., D. Kaufman, D. Nuzhnyy, O. Bar-Yosef \& M. Weinstein-Evron. 2013. Variability of lunates and changes in projectile weapons technology during the Natufian, in O. Bar-Yosef \& F.R. Valla (ed.) Natufian foragers in the Levant: Terminal Pleistocene social changes in Western Asia: 671-84. Ann Arbor (MI): International Monographs in Prehistory.

Yeshurun, R., G. Bar-Oz \& D. Nadel. 2013. The social role of food in the Natufian cemetery of Raqefet Cave, Mount Carmel, Israel. Journal of Anthropological Archaeology 32: 511-26. https://doi.org/10.1016/j.jaa.2013.09.002

Yeshurun, R., G. Bar-Oz \& M. Weinstein-Evron. 2014. Intensification and sedentism in the Terminal Pleistocene Natufian sequence of el-Wad Terrace (Israel). Journal of Human Evolution 70: 16-35. https://doi.org/10.1016/j.jhevol.2014.02.011

Received: 8 June 2016; Accepted: 30 August 2016; Revised: 10 September 2016

(C) Antiquity Publications Ltd, 2017 